\title{
LUCHTVAART IN GUYANA
}

DOOR

JHR. L. C. VAN PANHUYS.

De bekwame samensteller van het artikel, in dit tijdschrift, over de mogelijkheid van een economische waardebepaling van Suriname met behulp van vliegtuigen, de thans naar Spitsbergen vertrokken mijningenieur E. C. Abendanon (zie De West-Indische Gids jaargang 1, blz. 165-174), heeft niet kunnen vermoeden hoe spoedig - haast tegelijkertijd met het neerschrijven van zijn studie - zijn toekomstdroom, ten minste voor een deel, tot een begin van uitvoering zou komen. Alleen maar, niet in Suriname, doch in de nabuurkolonie, Cayenne of Fransch-Guyana.

Een, eerst dezer dagen, hier te lande ontvangen exemplaar van het ambtelijk verslag van de vergadering van den "Conseil Général" van 16 Augustus 1919, bijlage van het Journal Officiel van de Kolonie van 17 April 1920, leert dienaangaande het volgende. Het Statenlid Saccharin, voorzitter van de Commissie van Rapporteurs, las in die vergadering een brief voor van den kapitein-luitenant (thans kapitein) ter zee Dutertre, administrateur, afgevaardigd door de vereeniging „Transports Aériens Guyanais” van 21 Juli t. v. aan den Gouverneur van Fransch-Guyana. Daarin staat, dat de vliegtuigen van de vereeniging zullen worden benut tot twee wel van elkander te onderscheiden doeleinden namelijk voor:

$1^{\circ}$. verkennings- en opnemingsdienst (kartografische opname);

$2^{\circ}$. Regelmatig luchtverkeer voor reizigers en 
goederen, op na ernstig onderzoek in te richten vaste lijnen.

De kartografische opname, schrijft de heer Dutertre, is blijkbaar voor de Kolonie van belang. Ik gevoel mij in staat om, door fotografie uit de lucht en met toepassing van de bij het leger-vliegtuig gebruikelijke werkwijzen, alle stroomgebieden van Fransch-Guyana in kaart te brengen, de nog onbekend geblevenen daaronder begrepen, mits men het noodige materieel te mijner beschikking stelt. Een gedeelte van het in den oorlog gebruikte materieel, namelijk vliegtuigen, toestellen voor luchtfotografie en voor telegraaf zonder draad, en draagbare vuurwapenen, voor de persoonlijke veiligheid van de vliegeniers, zouden door de Regeering kosteloos kunnen worden afgestaan.

Al dat materieel zou ter beschikking kunnen worden gesteld van onze Vereeniging op voorwaarde, dat wij volledige kaarten vervaardigen van de stroomgebieden van Guyana, met dat van de Marowijne te beginnen.

De heer D. acht het noodig, dat de Kolonie aan den Minister van Oorlog vraagt, om:

20 watervliegtuigen, Georges Lévy dits Le Pen, hydravions, gereed om te vliegen en voorzien van motoren 300 H.P. Renault, zee-type;

het voor deze vliegtuigen benoodigd reservemateriaal, met tien reserve-motoren $\mathrm{H}$. P. Renault, zee-type;

10 toestellen Telegraaf Z.D. voor vliegtuigen;

7 toestellen op de aarde, teneinde met de vliegtuigen in verbinding te blijven, welke toestellen waren te plaatsen te Cayenne, te St.-Laurent, op de landingsplaatsen voor vliegtuigen van de verschillende rivieren, de Oyapoc, de Sinnemary, de Mana en de Inini;

het fotografisch en kartografisch materieel, noodig voor den arbeid met vijf vliegtuigen in de lucht; 10 lichte karabijnen met patronen.

Wat nu het personen- en goederenvervoer aangaat, wil de heer $\mathrm{D}$. vaste lijnen inrichten op alle rivieren 
van de Kolonie, naarmate de verkennings- en opnemingsdienst die met de grootste waarborgen heeft kunnen voorbereiden. Wij zullen beginnen met de eenvoudigste lijn: St.-Laurent-Inini-Ouaqui, die wij zullen uitbreiden naar de Boven-Marowijne, en tot alle rivieren. Wij hopen op die wijze het noodige kapitaal en de onmisbare arbeidskrachten naar de Kolonie te trekken. De Ministers van Oorlog, van Koloniën en van Marine hebben het belang van onze pogingen erkend, en mij naar Guyana gezonden, hoewel de vrede nog niet is geteekend. De genoemde Ministers willen geldelijken en anderen steun verleenen, mits de Kolonie verklaart, het belang van de zaak in te zien en, naarmate van haar krachten, een subsidie toezegt. Er zijn vele antecedenten. De Vereeniging van de „Messageries aériennes", Parijs-Lille, en Lacécaver in Marokko, werken met kosteloos in gebruik afgestane vliegtuigen, op voorwaarde dat de Regeering zoo noodig over een deel dadelijk bij eersten oproep kunne beschikken. Zij worden bovendien geldelijk gesteund. Madagaskar en Indo-China hebben op hunne begrooting een bescheiden bedrag voor de luchtvaart uitgetrokken en het ontbrekende wordt door het Moederland bijgepast.

Daar de vereenigingen in Frankrijk slechts vliegdiensten kunnen inrichten, wanneer zij de vliegtuigen kosteloos ontvangen, moet voor Fransch-Guyana te eerder dezelfde voorwaarde worden gesteld, te meer ook, omdat de kosten van verpakking en verzending bijna 8000 francs per vliegtuig bedragen, de emballage alleen kost 3500 francs.

Ik heb dus, mijnheer de Gouverneur, zoo eindigt de brief van den heer $\mathrm{D}$. de eer $\mathrm{U}$ te vragen:

A. om in een ambtelijk schrijven te doen uitkomen, welk belang de Kolonie heeft bij het kunnen beschikken over 20 vliegtuigen, om bijvoorbeeld in gevallen van ongeregeldheden in de strafinrichtingen, tot het vaststellen van grenzen van concessiën, bij opstootjes op de placers, voor het 
tegengaan van den smokkelhandel, troepen, politiebeambten, ambtenaren van het mijnwezen en van de belastingen vlug te kunnen overbrengen. Uw schrijven zal dan een aanvraag, die ik zal doen, ondersteunen, om in het geheel 80 vliegtuigen, namelijk 20 in het gebruik, 20 in herstelling of bewaring en 40 in voorraad in Frankrijk (type Georges Lévy 300 H.P. Renault, dan wel Tellier 330 H.P. Sunheam) met motoren en materieel ter verwisseling.

B. Een subsidie te verzoeken van 250.000 francs, bestemd om ongeveer 30 vliegtuigen te kunnen inpakken en verzenden, waarvan een deel door de Kolonie naar reden van hare krachten en de rest door den Minister van Koloniën en den Burgerlijken Vliegdienst wordt betaald.

C. Vrijstelling te verleenen van alle tolrechten.

D. Aan de vereeniging kosteloos het noodige terrein te verschaffen.

E. Zooveel mogelijk bijstand te verleenen door den arbeid van gestraften.

Daarop werd een brief voorgelezen, van den kapiteinluitenant ter zee Dutertre aan den Minister van Koloniën van 30 Mei 1919, waaruit valt af te leiden, dat de heeren Rivanc en Clanis, alsmede fabrikanten van vliegtuigen, en ook kooplieden te Cayenne, bereid zijn tot geldelijke bijdragen; dat het eerst noodige materieel uit den op te ruimen legervoorraad zal worden overgenomen met $70 \%$ reductie, dat gerekend wordt dat het Ministerie van Koloniën de overtochtskosten voor personeel en materieel zal betalen, en dat de fotografietoestellen enz. van het Ministerie van Oorlog ter leen zullen worden ontvangen.

Behalve met de vervaardiging van een kaart, wil de vereeniging zich belasten met een postdienst in de Kolonië en met het kosteloos vervoer van ambtenaren door de lucht boven het grondgebied der Kolonie.

Het verslag van den rapporteur uit de Staten is - 
geen wonder - in zeer geestdriftigen toon gesteld. Wij zullen niet alleen wetenschappelijke doeleinden kunnen volgen, zoo drukt de heer Saccharin zich uit, maar de zoo lang gewenschte orde en den arbeid in het binnenland kunnen bevorderen.

Niet alleen om het nieuwe te huldigen maar wel degelijk om het land economisch te ontwikkelen stelt de Commissie van Rapporteurs voor een subsidie van 30.000 francs per jaar te verleenen, het betreurende dat de geldelijke toestand van de Kolonie haar niet toelaat om meer te doen. Met groote warmte wordt de kapitein ter zee Dutertre, die de vergadering bijwoonde om inlichtingen te kunnen geven, bedankt.

„Ces paroles sont couvertes d'applaudissements auxquels le public prend part."

Bij de gedachtenwisseling wordt gevraagd, of de voorgestelde prijs van 2 francs per K.G. per luchtvaartuig niet te hoog is. Het vliegtuig zou personeel en goederen, van een expeditie naar de goudvelden, landen aan de mondingen van de kreken; het vervoer per corjaal, van de rivier door de kreek naar het placer, zou dus blijven bestaan. De Boschneger - het vervoer naar de goudvelden in Fransch-Guyana geschiedt in hoofdzaak door Boschnegers uit Suriname, die tijdelijk naar de Fransche kolonie trekken -, vraagt, voor het vervoer van een ton vracht in zijn corjaal, 1000 francs; het vliegtuig zou 2000 francs per ton eischen. Er blijft dan, voor het vervoer door de kreken, stel 40 transporten van één persoon, of van een vat of daarmede gelijkgestelde hoeveelheid goederen, tegen 36 francs, in het geheel 1440 francs. Per ton zou dus het vervoer, van de hoofdplaats naar het placer, kosten $2000+$ 1440 , dat is 3440 francs, indien van een vliegtuig gebruik werd gemaakt en $1000+1440$, of 2440 francs, per Boschnegercorjaal.

De heer Dutertre, die werd uitgenoodigd naast den gedelegeerde van het Bestuur plaats te nemen, wees er op, dat de reizen van 40 dagen per corjaal gedurende welke men personeel, en bemanning van het corjaal, 
moet voeden, onnoodig zouden worden. Men diende voorts rekening te houden met het aan de lange reizen verbonden verlies en bederf van eetwaren en goederen; op het voordeel van de magazijnen, die in het binnenland zouden worden opgericht en per vliegtuig geproviandeerd, op het voordeel voor den kleinen man om alles nagenoeg ter plaatse te kunnen koopen. Natuurlijk zou het vliegtuig moeten trachten met de corjaal te concurreeren; van de deelneming, die de vereeniging zou trachten op alle wijzen te bevorderen, zou afhangen of de vervoerprijzen per vliegtuig zouden kunnen worden verlaagd.

Met geestdrift werd het voorstel van de Commissie van Rapporteurs met algemeene stemmen aangenomen.

Nog geen vier maanden later, op 8 December 1919, kon de Gouverneur van Fransch-Guyana in zijn openingsrede van de 78ste zitting van den „Conseil-Général” er op wijzen, dat de „Société des Transports Aériens Guyanais" met succes had gearbeid. Hare vliegtuigen hadden verscheidene malen het traject Saint-Laurent - Cayenne, en omgekeerd, in minder dan twee uren volbracht, en de verbinding tusschen St.-Laurent en de Inini, die per corjaal 14 dagen tot drie weken vorderde, was in denzelfden tijdsduur tot stand gekomen.

Wat beteekent deze snelheid, indien een vliegdienst van Paramaribo zou kunnen uitgaan? Dat men in minder dan tien minuten op het fort Nieuw-Amsterdam; in een kwartier of 20 minuten op Braamspunt of op post Groningen, binnen het uur (Amerikanen, hoort!) op Moengo zou kunnen wezen, in één uur op Kabelstation, of Coronie; dat Nickerie binnen de twee uren zou kunnen worden bereikt.

Vestigen wij echter onze aandacht op het in FranschGuyana reeds verkregene.

Welke ervaringen zijn op de Fransche vliegtochten opgedaan? Zij zijn naar wij meenen noch hier te lande, noch in de kolonie bekend, terwijl toch de aangelegenheid voor Suriname in de toekomst van veel belang kan zijn. 
Het is wel zeer waarschijnlijk, dat de Fransche vliegeniers op hunne tochten naar de Inini de rivier (Marowijne en Lawa) hebben gevolgd en niet linea recta van St.:Laurent over het oerwoud naar de monding van de Inini zijn gevlogen en dat, bij de tochten van St.-Laurent naar Cayenne, de zee den weg zal hebben aangegeven. Was aan de Inini-monding een baken opgesteld? Welke invloeden heeft men van den passaatwind en van onweders ondervonden. Zijn er nadeelen bij het landen voortgevloeid uit de aanwezigheid van rotsen in de rivier?

Uit den door den Franschen Gouverneur opgegeven vliegtijd volgt nog, dat het voor de vliegtuigen mogelijk zal zijn den afstand van St.-Laurent naar Paramaribo binnen anderhalf uur af te leggen. Ligt het niet op den weg van het Bestuur de Fransche vliegers tot zulk een triomftocht uit te noodigen en zal dan een met vlaggen getooid Paramaribo de geniale baanbrekers naar verdienste huldigen?

Wat de kaartvervaardiging betreft, door fotografie uit de lucht, hoede men zich voor een te gunstige voorstelling.

In het Jaarverslag van den Topografischen Dienst in Nederlandsch-Indië over 1918 vermeldt de heer L. F. van Gent in zijn artikel „Fotografie ten dienste van kaarteeringen" dat reeds in 1910 door Dr. Wegener het plan werd ontworpen om Duitsch N.-Guinea stelselmatig te exploreeren met behulp van ballonfotografie. Oorspronkelijk, zegt de heer v. G., kleefde aan de ballon- en vliegerfoto's het nadeel, dat zij te veel gesluierd waren; de tegenstellingen tusschen licht en donker niet uitkwamen; de natuur maakt lichte voorwerpen geelachtig, donkere blauwachtig. Dit werd wel opgeheven door kleur-filters, welke het geel onverzwakt doorlieten en het blauw absorbeerden, doch daar de hemel witblauw is, kan de sluier niet geheel worden weggenomen, maar toch wel zooveel, dat de foto's bij krachtige ontwikkeling bruikbaar zijn. In Frankrijk worden zelfs, zoowel van $4000 \mathrm{M}$. hoogte als bij een 
vliegsnelheid van 100 K.M. nog bruikbare cliché's verkregen. Wel acht de heer v. G. dat de woorden in 1909, door den heer Sachse in het orgaan der Indische Krijgskundige vereeniging No. 24 geschreven nog gelden, dat in de gelijkvormige zee van groen, vooral indien men met kleurfotografie werkt, de loop van rivieren wel degelijk door foto's uit een ballon of vlieger genomen, kan worden vastgesteld, maar hij is van oordeel, dat ten behoeve van de regelmatige karteeringen de fotografie evenwel weinig diensten zal kunnen bewijzen. De bovenvermelde elders gedeeltelijk overwonnen bezwaren zullen ook in Indië worden gevoeld, tevens omdat kale, rotsachtige bergpartijen, waarin de fotogrammetrie op hare plaats zou zijn, weinig voorkomen; de triangulatie zeer ijl is of ontbreekt; de groote heiigheid van de lucht het fotografeeren in hoogere mate belemmert dan elders en wegen slechts zelden zullen te onderscheiden zijn. Bovendien bestaat in Indië geen gelegenheid voor het verrichten van eventueele reparaties aan instrumenten, zoo mechanisch ingewikkeld als een comparateur.

In de "Geographical Review" van Februari 1917, blz. 91-106, heeft Dr. E. Mjöberg een plan tot onderzoek door middel van vliegtuigen van Nieuw-Guinea voorgesteld, waarbij gerekend wordt op kaartvervaardiging, ook uit de lucht, door foto-topografie, en met een cinematograaf.

In de vergadering van de Maatschappij tot Bevordering van het Natuurkundig Onderzoek der Nederlandsche Koloniën van 21 Juni 1919, deelde de waarnemende voorzitter, de Hoogleeraar Dr. Max Weber mede, dat in het jaar 1918, in den boezem van het Bestuur bij herhaling plannen ter sprake kwamen, in hoever het mogelijk zou zijn een topografische verkenning van Nieuw-Guinea te vergemakkelijken, als gebruik gemaakt kon worden van het meest moderne hulpmiddel op dit gebied: het vliegtuig. Het Bestuur had daarom gaarne de gelegenheid aangegrepen om door bij uitstek deskundigen, de heeren A. H. G. Fokker 
en E. Diemer te worden voorgelicht. Deze hielden in dezelfde vergadering hunne voordrachten over „Vliegtuigen ten dienste van de topografische terreinopname" en "Topografische terreinopname door middel van stereo-fotogrammetrie".

De heer Fokker wees er op, dat de luchtfotografie zonder den oorlog niet op de hoogte van volkomenheid zou zijn gekomen, waarop ze nu staat; dat de hedendaagsche vliegtuigen, mede in verband met den oorlog, eenzijdig zijn ontwikkeld, en dat op de gedurende den oorlog verkregen ervaringen verder moet worden gebouwd: vliegtuigen en fototoestellen moeten worden verbeterd en ook de ontwikkelingsmethode moet worden vervolmaakt. Hij eindigde met den wensch, dat onze Regeering er toe moge besluiten de nog zoo uitgestrekte gebieden van Oost en West door middel van het vliegtuig in kaart te brengen. De heer Diemer kon aantoonen, dat de topografische terreinopneming met behulp der fotografie, door de fotogrammetische bewerking van uit de lucht genomen foto's in vergelijking met vroeger een zeer grooten vooruitgang beteekent, niet alleen omdat de kosten aanzienlijk geringer geworden zijn, maar vooral omdat de snelheid der opneming ten minste met het twaalfvoud vermeerderd is.

Thans zien wij naar de zijde van Britsch-Guyana. De in die kolonie verschijnende Daily Argosy, maileditie van 28 Febrauri 1920, meldt, dat door kapitein Thomas van het „Royal Flying Corps” een plan is ontworpen voor de oprichting van een „West-Indian Air Service" tot het vervoer van personen, mails en goederen tusschen eenige West-Indische eilanden en Venezuela. Op Trinidad zou het hoofdkwartier zijn; het te bezigen vliegtuig de „Handley Page twin-engine F 5 flying boat", hetwelk tien passagiers of 2000 lbs. vracht zal kunnen dragen. Het benoodigde kapitaal zou worden bijeengebracht door zakenmenschen op Trinidad en door de „Handley Page Company”. De lijnen zouden loopen over Port- of Spain, Tobago, 
St.-Vincent, Grenada, Barbados, Venezuela en BritschGyuana. Dezelfde firma heeft reeds eene verbinding tusschen Buenos-Aires en Pernambucco tot stand gebracht en voor de toekomst wordt gedacht aan een lijn van New-York naar Buenos-Aires, waarvan dan de West-Indische Vliegdienst mogelijk een deel zal kunnen uitmaken. Een wekelijksche dienst zal worden ingesteld naar Tobago, St.-Vincent, Grenada en Barbados, en naar een haven van Venezuela, daarna zal de dienst kunnen worden uitgebreid tot Britsch-Guiana.

Kapitein Thomas vertrekt, zoo schreef de Argosy, van Trinidad naar Caracas, om regelingen voor een vliegdienst in Venezuela te treffen, namelijk voor een lijn van Cumana naar Puerto Cabello, via Barcelona en Caracas; ook hoopt hij in Columbia een lijn tusschen Bogota en Barranquilla te kunnen inrichten. Een Fransche vliegmaatschappij is al met de voorbereiding van een vliegdienst naar laatstgenoemde stad bezig. Er wordt gedacht over een andere „Handley Page Service", tusschen Cartagena en St.-Martha, en deze dienst zal mogelijk verbinding krijgen met de voorgestelde nieuwe havenwerken aan de golf van Dariën.

Mochten deze luchtlijnen tot ontwikkeling zijn gekomen dan zal, zoo besluit de Argosy, de West-Indische lijn de belangrijke schakel zijn in alle diensten tusschen Noord- en Zuid-Amerika, en naar het Noorden ook aansluiten aan de lijn die men tusschen New-York en Porto Rico wil tot stand brengen.

In de kolonie Curaçao dus, niet minder dan in de kolonie Suriname, is in de naaste toekomst bezoek van vliegtuigen te wachten. Blijkt het op den duur mogelijk luchtverbindingen tusschen de Guyana's en Brazilië te onderhouden - het oerwoud tusschen een plaats als b.v. St.-Laurent en aan de Amazone gelegen steden en plaatsen als Obidos, Santarem, San José, Macapa, zou, naar oppervlakkige schatting, in een 10-tal uren kunnen worden overgevlogen, het traject naar Manaos in 12 uren - dan zal er ook van geestelijk en stoffelijk 
verkeer, tusschen Suriname en het vooruitstrevende Brazilië in de toekomst sprake kunnen zijn. Men staat aan het begin van een nieuw tijdperk. Nog geen honderd jaren geleden kwam de eerste stoomboot in Suriname en werd daar met geestdrift ontvangen; dat nu de komst van het eerste vliegtuig voor de kolonie een tijdperk van nog grooter belang inluide.

De Surinaamsche maagd zat totnogtoe, veelal lusteloos, met den rug naar de hellingen van het Toemoek Hoemak gebergte gekeerd, zij staarde naar het Noorden en scheen alles te verwachten van overzee. Moge zij hare schoone donkere oogen nu ook opslaan naar boven en rondziende naar de naburige staten, kunnen hopen, dat zij eenmaal in bloeiende zelfstandigheid, eene eereplaats zal kunnen innemen onder de van levenslust bruischende volken van de Nieuwe Wereld.

Naschrift. De heer W. F. Willis, die belast is geweest met een opneming van een deel van den luchtweg van Kairo naar de Kaap, geeft in het „Geographical Journal" van Juni 1920, bladz. 459-464 een overzicht van zijn bevindingen bepaaldelijk in Egypte en de Soedan, dat van belang kan zijn voor een beoordeeling van het vraagstuk van de luchtvaart in Suriname en de verbinding van de Kolonie met andere landen.

Daarin wordt opgemerkt, dat het instellen van een luchtdienst, veel meer om het lijf heeft, dan een leek zich kan voorstellen. In Afrika wenscht men landingsplaatsen op ongeveer 100 (Eng.) mijlen van elkander, met de noodige petroleum-vul-stations, woningen voor stuurlieden en technische arbeiders en installaties voor telegraaf zonder draad. Op iedere landingsplaats zou ongeveer 800 vierkante yards ruimte moeten zijn voor opstijgen en dalen, met een vaste en harde oppervlakte. 
In woestijnen zijn zulke ruimten gemakkelijk aan te leggen door het maken van groote witte cirkels, met vlaggen of kleine witte blikken om de grenzen aan te geven. In het boschland moeten boomen en struikgewas geveld en gebrand worden, stronken en stompen worden opgeruimd, mierenheuvels worden vernield en de geheele oppervlakte hard gemaakt; zachte grond is zeer slecht voor een landing. Hooge boomen in de nabijheid van de grenzen moeten ook worden geveld. Het schoonhouden van het terrein vergt weder veel arbeid.

Het bleek tusschen Khartoem en Oegande wenschelijk den Nijl zoo nabij mogelijk te volgen; de rivier is de eenige goede loods voor den vliegenier.

De Sudd-streek, een onafzienbare woestenij van groen papyrus-gras van 10 tot 15 voet hoog, dat uit het Nijlwater opgroeit, moet voor een luchtweg worden gemeden, want de bemanning der aeroplaan die hier zou neerdalen, zou zich niet kunnen redden.

Zandstormen in den zomer in Egypte en electrische stormen ten zuiden van Khartoem, alsmede tropische regenbuien en boschbranden, die de landbakens onzichtbaar maken, maken het oprichten van een regelmatige luchtlijn Kaap-Kairo naar het oordeel van den heer Willis onzeker.

Hij legt er den nadruk op, dat in een land, met het bijzondere klimaat en den ongunstigen bodem van Afrika de oplossing voor een vliegdienst zal moeten worden gevonden in de samenstelling van zoo krachtige machines dat de noodige brandstof kan worden medegenomen en lange vluchten zonder tusschenstations kunnen worden volbracht. 